\title{
Morin Induces Melanogenesis via Activation of MAPK Signaling Pathways in B16F10 Mouse Melanoma Cells
}

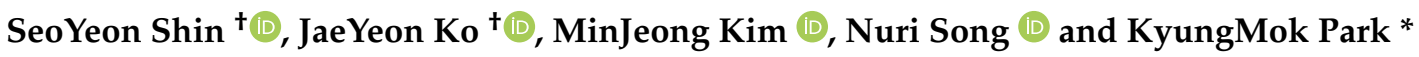 \\ Department of Pharmaceutical Engineering, Dongshin University, 185 gunjae-ro Naju, Jeonnam 58245, Korea; \\ ssy33144@naver.com (S.S.); cp8340@naver.com (J.K.); 6760933@naver.com (M.K.); nuri980424@naver.com (N.S.) \\ * Correspondence: parkkm@dsu.ac.kr; Tel.: +82-61-330-3273 \\ + These authors equally contributed to the work.
}

Citation: Shin, S.; Ko, J.; Kim, M.; Song, N.; Park, K. Morin Induces Melanogenesis via Activation of MAPK Signaling Pathways in B16F10 Mouse Melanoma Cells. Molecules 2021, 26, 2150. https://doi.org/ $10.3390 /$ molecules 26082150

Academic Editor: Alexandru Mihai Grumezescu

Received: 5 March 2021

Accepted: 1 April 2021

Published: 8 April 2021

Publisher's Note: MDPI stays neutral with regard to jurisdictional claims in published maps and institutional affiliations.

Copyright: (c) 2021 by the authors. Licensee MDPI, Basel, Switzerland. This article is an open access article distributed under the terms and conditions of the Creative Commons Attribution (CC BY) license (https:// creativecommons.org/licenses/by/ $4.0 /)$.
Abstract: Morin is a well-known flavonoid, and has been reported to have various properties, such as anti-cell death, antioxidant, and anti-inflammatory properties. Although studies on the biochemical and biological actions of morin have been reported, the melanin biosynthesis effects and molecular mechanisms are unknown. In this study, we first found that morin has the effect of enhancing melanin biosynthesis in B16F10 mouse melanoma cells, and analyzed the molecular mechanism. In this study, we examined the effects of morin on the melanin contents and tyrosinase activity, as well as the protein expression levels of the melanogenic enzymes TRP-1, TRP-2, and microphtalmia-associated transcription factor (MITF) in B16F10 mouse melanoma cells. Morin showed no cytotoxicity in the concentration range of 5-100 $\mu \mathrm{M}$, and significantly increased the intracellular tyrosinase activity and melanin contents. In mechanism analysis, morin increased the protein expression of TRP-1, TRP-2, and MITF associated with melanogenesis. Furthermore, morin increased phosphorylated ERK and p38 at the early time, and decreased phosphorylated ERK after $12 \mathrm{~h}$. The results suggest that morin enhances melanin synthesis through the MAPK signaling pathways in B16F10 mouse melanoma cells.

Keywords: morin; melanin; tyrosinase; TRP-1/2; MITF; ERK; p38

\section{Introduction}

Vitiligo is a skin depigmentation disorder. It has been reported that $0.5-1 \%$ of the world's population has this disease, regardless of race or gender [1-3]. This skin disease occurs when cutaneous melanocytes are destroyed or non-functional [4,5]. Melanin is produced by melanosomes in the melanocytes, and is scattered in the basal layer of the epidermis. Melanin is an essential component of skin pigmentation, and plays an important role in preventing UV damage [6].

Melanogenesis is regulated by melanogenic enzymes, such as tyrosinase (TYR), tyrosinase-related protein 1 (TRP-1), and tyrosinase-related protein 2 (TRP-2) [7]. Tyrosinase plays a pivotal role in melanogenesis by the hydroxylation of tyrosine into dihydroxyphenylalanine (DOPA), followed by further oxidation of DOPA to DOPA quinone. TRP-2 acts as a dopachrome tautomerase, and catalyzes the rearrangement of dopachrome to form 5,6-dihydroxyindole-2-carboxylic acid (DHICA), and TRP-1 oxidizes DHICA to produce carboxylate indolequinone [8-11].

Microphthalmia-associated transcription factor (MITF) is a major regulator of the transcription of genes involved in melanin synthesis. Several signaling pathways mediate melanogenesis [12,13]. The p38 mitogen-activated protein kinase (p38 MAPK) and c-Jun $\mathrm{N}$-terminal kinase mitogen-activated protein kinase (JNK MAPK) pathway may upregulate melanogenesis by increasing MITF expression. The extracellular signal-regulated kinase mitogen-activated protein kinase (ERK MAPK)-dependent MITF expression pathway is also involved in melanogenesis [14,15]. 
Morin ( $2^{\prime}, 3,4^{\prime}, 5,7$-pentahydroxyflavone) is a well-known flavonoid found naturally in various fruits, mulberries, almonds, red wine, and many Chinese herbs [16-18]. Previous studies have reported that morin has anti-cell death, antioxidant, and anti-inflammatory properties [19-21]. The biochemical and biological actions of morin have been studied, but the effects of melanin synthesis and its mechanism of action are unknown. Therefore, this study focused on analyzing the effect of morin on melanin biosynthesis and its molecular mechanism in B16F10 mouse melanoma cells.

\section{Results}

\subsection{Effects of Morin on Cell Viability}

To assess the cytotoxicity of morin (Figure 1a), cell viability was measured by MTT assay in B16F10 mouse melanoma cells. Morin was incubated at various concentrations $(5-100 \mu \mathrm{M})$ for $48 \mathrm{~h}$ at $37^{\circ} \mathrm{C}$ in a $5 \% \mathrm{CO}_{2}$ incubator. It did not affect cell viability at any concentration compared to the control (Figure 1b).<smiles>O=c1c(O)c(-c2ccc(O)cc2O)oc2cc(O)cc(O)c12</smiles>

(a)

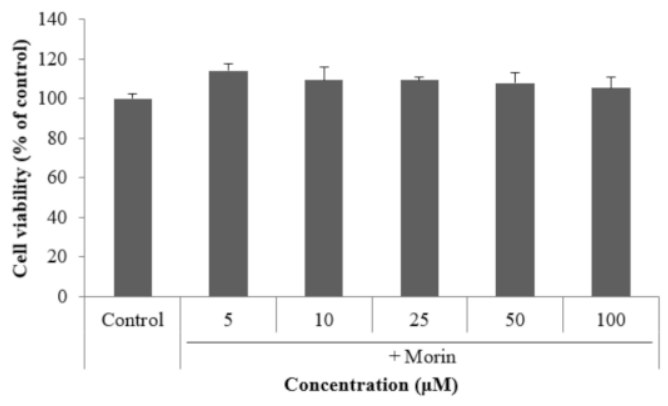

(b)

Figure 1. (a) Chemical structure of morin. (b) Effect of morin on the viability of B16F10 mouse melanoma cells. Cells were treated with morin $(5,10,25,50$, and $100 \mu \mathrm{M})$ for $48 \mathrm{~h}$. The data are presented as the mean \pm SD of at least three independent experiments.

\subsection{Effects of Morin on Melanin Contents}

Cytotoxicity and melanin content measurements in B16F10 mouse melanoma cells were performed at $25-100 \mu \mathrm{M}$ of morin. Melanin content increased in a concentrationdependent manner (Figure 2a). Morin showed a higher melanin content at $50 \mu \mathrm{M}$ than the positive control $\alpha$-MSH $(100 \mathrm{nM})$. In addition, the color change was visually confirmed in the pellets of the treated groups (Figure 2b). Morin showed a darker pellet than that of a-MSH at $50 \mu \mathrm{M}$.

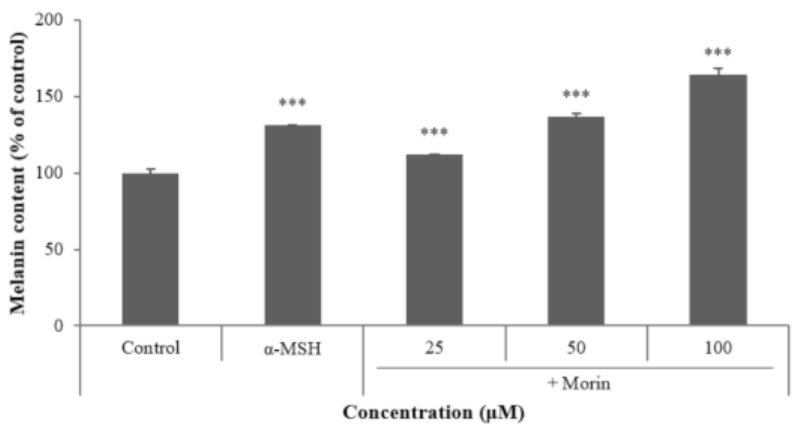

(a)

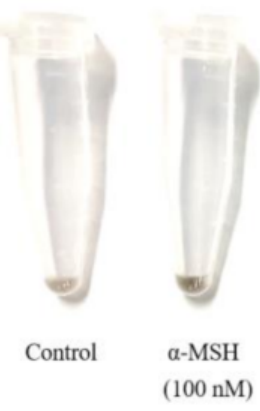

$(100 \mathrm{nM})$

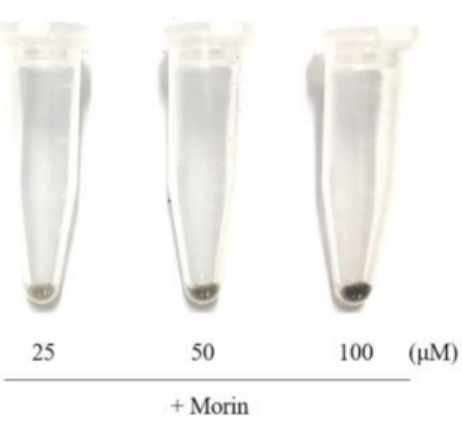

(b)

Figure 2. (a) Effect of morin on melanin contents. B16F10 mouse melanoma cells were treated with morin (25, 50, and $100 \mu \mathrm{M})$ for $72 \mathrm{~h}$. (b) Cell precipitation following centrifugation is indicated; $\alpha$-MSH (100 nM) was used as the positive control. The data are presented as the mean \pm SD of at least three independent experiments; ${ }^{* * *} p<0.001$ compared with the control. 


\subsection{Effects of Morin on Mushroom and Intracellular Tyrosinase Activity}

L-DOPA was used as a substrate for tyrosinase activity to determine the effect of morin on mushroom tyrosinase activity. Morin was added at concentrations of 25, 50, 100, 250, and $500 \mu \mathrm{M}$. Morin significantly increased mushroom tyrosinase activity and intracellular tyrosinase in a concentration-dependent manner (Figure 3). These results indicated that morin directly and indirectly increased tyrosinase activity. Furthermore, morin implied the possibility of regulating the expression of melanogenic enzymes.

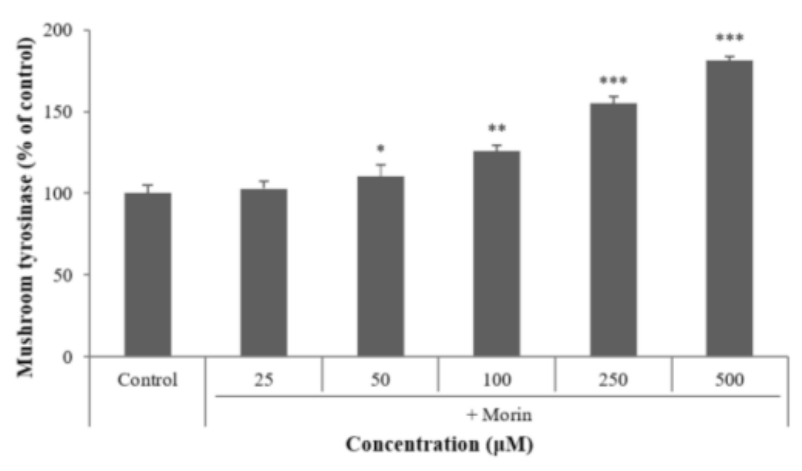

(a)

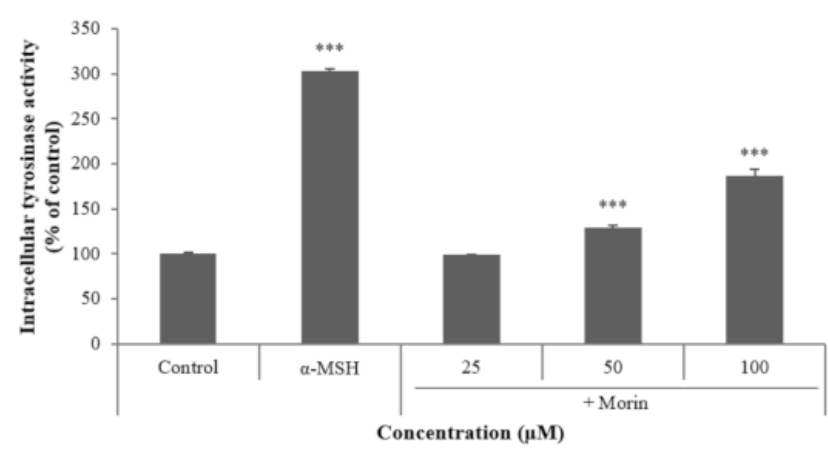

(b)

Figure 3. Effect of morin on tyrosinase activity. (a) The effects of morin on mushroom tyrosinase activity were determined as described in the Materials and Methods section. (b) B16F10 mouse melanoma cells were treated with morin (25, 50, and $100 \mu \mathrm{M})$ for $72 \mathrm{~h}$, and the intracellular tyrosinase activity was determined as described in the Materials and Methods section; $\alpha$-MSH $(100 \mathrm{nM})$ was used as the positive control. The data are presented as the mean \pm SD of at least three independent experiments; ${ }^{*} p<0.05,{ }^{* *} p<0.01,{ }^{* * *} p<0.001$ compared with the control.

\subsection{Effects of Morin on Melanogenic Enzymes}

The effects of morin on melanogenic enzymes were determined using western blotting. Morin induced the protein expression of TRP- 1 and TRP-2 in a dose-dependent manner. To understand TRP-1 and TRP-2 gene transcription, we examined the effect of morin on the expression of the major transcription factor MITF. The expression of MITF and melanogenesis-related proteins increased after treatment with morin (Figure 4). These results suggest that morin-induced melanin synthesis is mediated by the upregulation of melanogenic enzymes and MITF at the protein level.

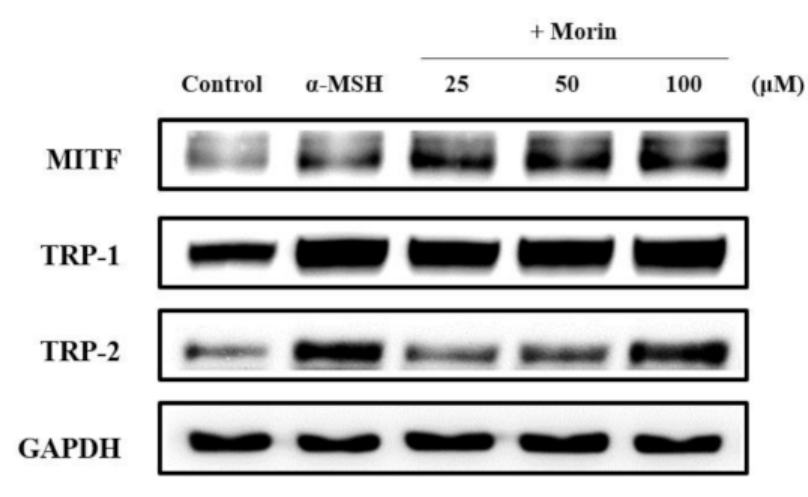

(a)

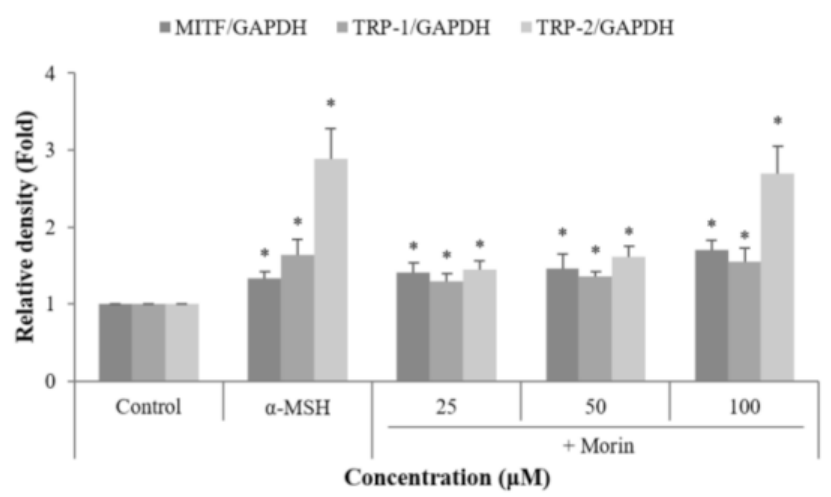

(b)

Figure 4. Effects of morin on the protein levels of melanogenic enzymes (TRP-1, TRP-2) and MITF. B16F10 mouse melanoma cells were treated with morin or $\alpha-\mathrm{MSH}$ at the indicated concentration for $24 \mathrm{~h}$. (a) MITF, TRP-1, and TRP-2 protein expressions were detected by western blotting. (b) Results were normalized against GAPDH expression. The data are presented as the mean $\pm \mathrm{SD}$ of at least three independent experiments; ${ }^{*} p<0.05$ compared with the control. 


\subsection{Effects of Morin on the Phosphorylation of ERK, JNK, and p38 in the MAPK Pathway}

We examined the MAPK signaling pathway to identify the molecular mechanism by which morin induces melanin production. As presented in Figure $5 \mathrm{a}, \mathrm{b}$, analysis of protein expression over time showed that phosphorylated ERK increased from 0 to $15 \mathrm{~min}$ and decreased after $15 \mathrm{~min}$. In addition, phosphorylated ERK decreased by treatment with morin at late time points (Figure $5 \mathrm{c}, \mathrm{d}$ ). Phosphorylation of p38 was stimulated by morin from 0 to $30 \mathrm{~min}$ (Figure $5 \mathrm{a}, \mathrm{b}$ ). We also confirmed the expression level of MAPK by treating morin at various concentrations $(25,50$, and $100 \mu \mathrm{M})$ for $30 \mathrm{~min}$. Phosphorylated ERK and p38 significantly increased the expression levels in a concentration-dependent manner (Figure $5 \mathrm{e}, \mathrm{f})$. However, the expression level of JNK was not increased by morin.

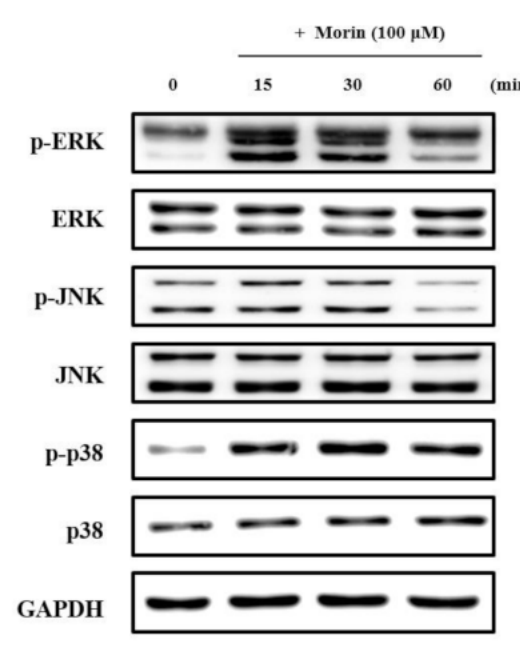

(a)

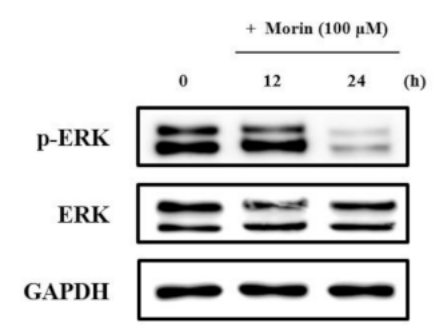

(c)

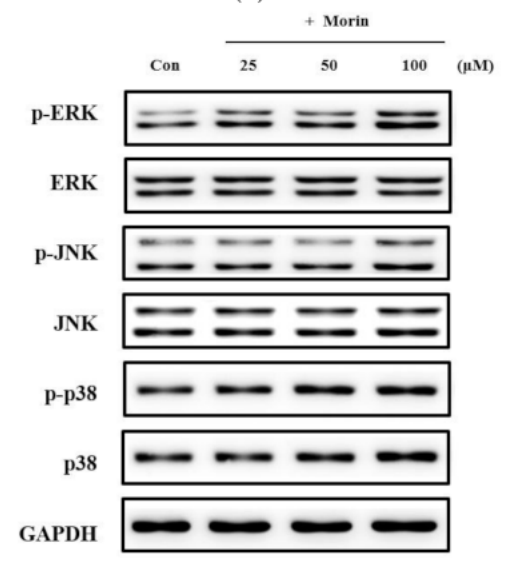

(e)

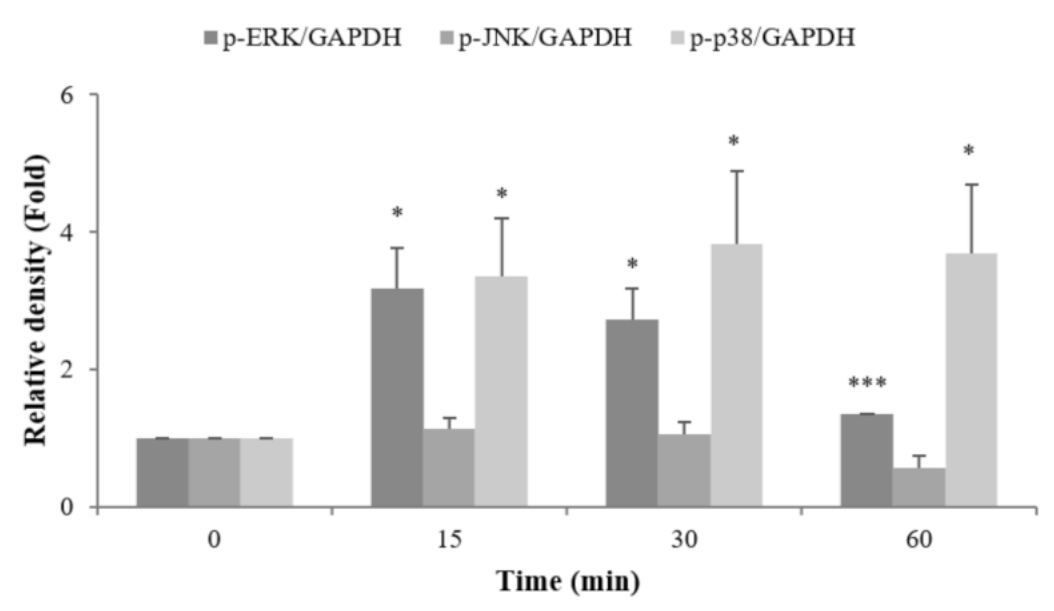

(b)

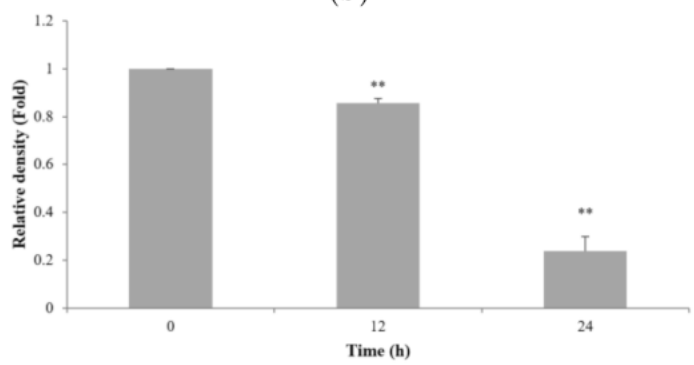

(d)

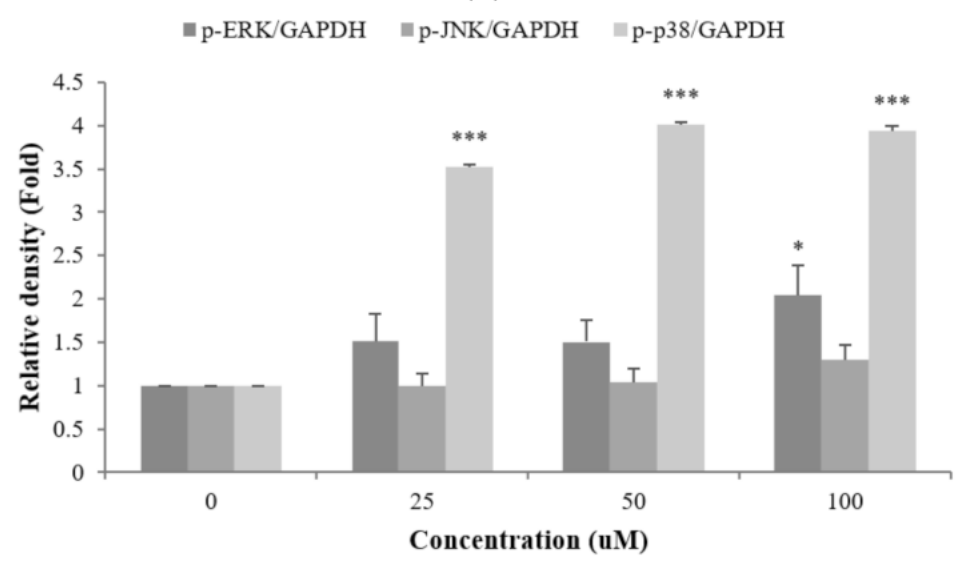

(f)

Figure 5. Effects of morin on the protein levels of phosphate ERK, JNK, and p38. B16F10 mouse melanoma cells were treated with morin at $(\mathbf{a}, \mathbf{c})$ various times, and (e) concentrations. Phosphate ERK, JNK, and p38 protein expression were detected by western blotting. (b,d,f) Results were normalized against GAPDH expression. The data are presented as the mean \pm SD of at least three independent experiments; ${ }^{*} p<0.05,{ }^{* *} p<0.01,{ }^{* *} p<0.001$ compared with the control. 


\subsection{Effects of Morin on MAPK Signaling by Specific Inhibitors}

To further confirm the role of the MAPK pathways in morin-induced melanin synthesis, we used the specific inhibitors ERK inhibitor (PD98059), JNK inhibitor (SP600125), and p38 inhibitor (SB203580). Cells were pretreated with specific inhibitors $1 \mathrm{~h}$ before the addition of morin, then incubated for $72 \mathrm{~h}$ for the measurement of melanin content. PD98059 (Figure 6a) and SB203580 (Figure 6c) inhibited the induction of melanin synthesis by morin. These result suggest that morin may cause melanin synthesis via ERK and p38 phosphorylation. However, the JNK inhibitor (SP600125) did not inhibit the induction of melanin synthesis by morin (Figure $6 b$ ).

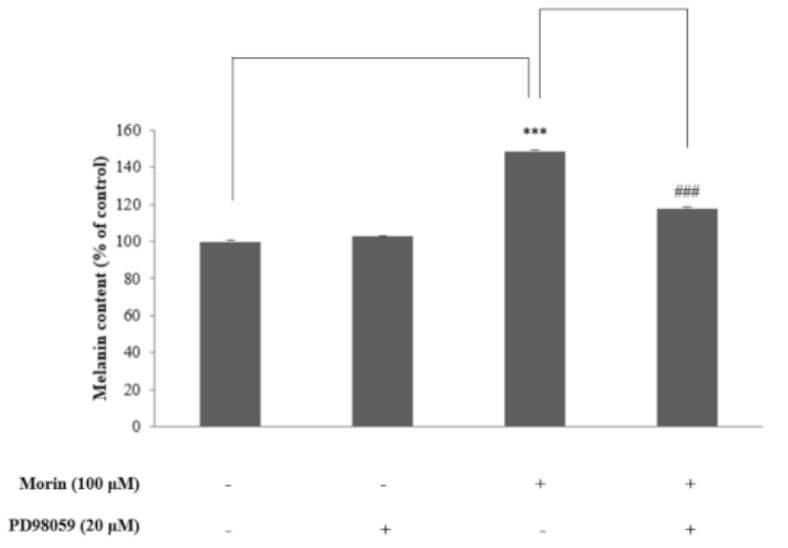

(a)

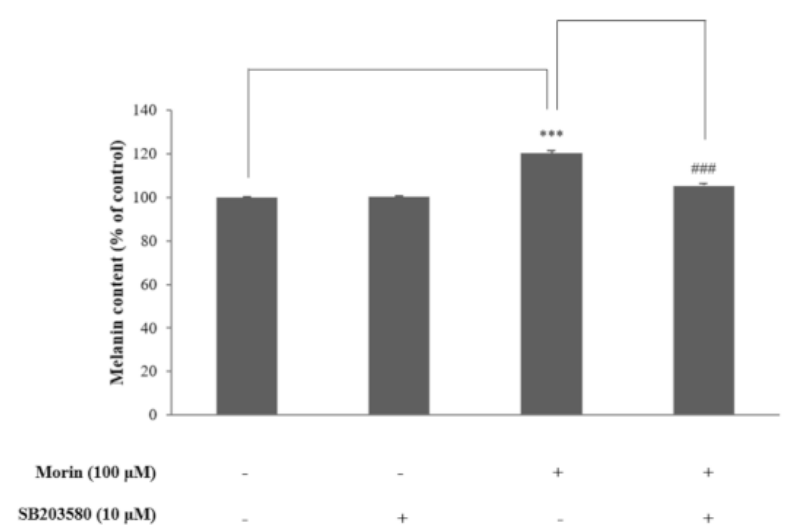

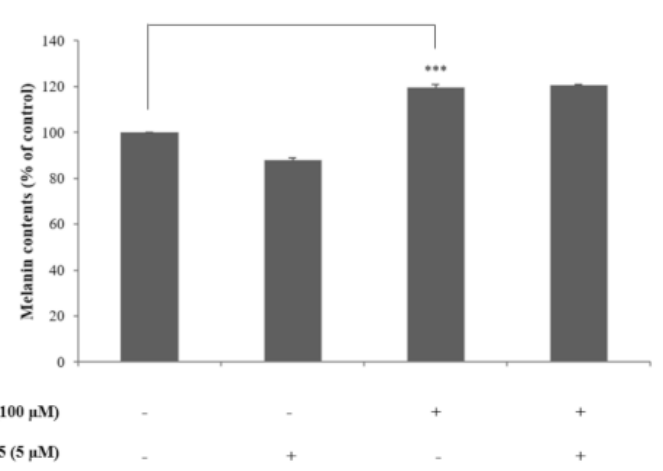

(b)

(c)

Figure 6. Effects of specific inhibitors of (a) ERK, (b) JNK, and (c) p38 on morin-induced melanin contents. Inhibitors (PD98059, SB203580) were pre-incubated with B16F10 mouse melanoma cells for $1 \mathrm{~h}$ before the addition of morin at $100 \mu \mathrm{M}$. The data are presented as the mean \pm SD of at least three independent experiments; ${ }^{* * *} p<0.001$ compared with the control. \#\# $p<0.001$ compared with morin stimulation.

\section{Discussion}

Melanin is an important determinant of human skin color that protects the skin from ultraviolet radiation and helps maintain body temperature. Additionally, the absence of melanocytes has been reported to cause skin diseases, such as vitiligo and albinism [22]. Although many melanogenesis inducers have been developed, they can cause serious side effects, such as allergies, contact dermatitis, eczema, and cytotoxicity [23]. Accordingly, many studies have been conducted on melanin biosynthesis and specific mechanisms for the development of new treatments for vitiligo [24,25].

Morin is a yellow compound that can be separated from the leaves of Maclura pomifera (Osage orange), Maclura tinctoria (Old Pustic), and Psidium guajava (Guava) leaves [26]. Morin has been shown to inhibit amyloid formation by islet amyloid polypeptide (amylin), 
decompose amyloid fibers, and inhibit IgE-mediated allergic reactions [27]. Morin treatment downregulated the expression of BLT2, NF- $\mathrm{kB}$, and Th2-cytokine (IL-1 $\beta$, IL-4, IL-6, IL-13, and TNF- $\alpha$ ) in the lungs of an allergic asthma rat model [28]. However, no study on melanin biosynthesis and the molecular mechanisms of morin has been conducted.

In this study, we investigated the effect of morin on melanin biosynthesis and its molecular mechanisms to understand the signal transduction pathways in B16F10 mouse melanoma cells. Morin was not toxic up to a concentration of $100 \mu \mathrm{M}$, and significantly increased the concentration-dependent activity of mushroom tyrosinase activity. Morin induced melanogenesis to increase melanin biosynthesis and intracellular tyrosinase activity in B16F10 mouse melanoma cells.

Melanogenesis is directly regulated by the major enzymes TRP-1 and TRP-2 [29]. In this study, morin significantly increased the expression of TRP-1 and TRP-2. Melanogenesis enzymes are regulated by MITF, a major regulator of melanocyte development and melanogenesis $[30,31]$. Morin upregulated MITF expression. Considering the appearance of the protein, the isoform of MITF protein is MITF-M. The molecular weight of MITF-M in melanoma cell lines is known to be $60-65 \mathrm{kDa}$ as a doublet, which represents different phosphorylation states of the protein [32]. Taken together, morin promoted melanin production by upregulating MITF and its downstream pathways, TRP-1 and TRP-2, in B16F10 mouse melanoma cells.

The mitogen-activated protein kinase (MAPK) signaling pathway is one of the major regulators of melanin biosynthesis because it is involved in the regulation of MITF expression and activation. ERK, JNK, and p38 are the major kinases mediated by several steps of activation or regulation of the MAPK pathway $[33,34]$. Changes in early expression of phosphorylated ERK are closely related to melanin production, and late activation of p-ERK activates phosphorylation of MITF at Ser 73, leading to ubiquitination and proteasome-mediated degradation of MITF, which is associated with the downregulation of melanogenesis [35-38]. JNK activation leads to cell differentiation, apoptosis, and melanin production in melanocytes, and p38 activation has been reported to be associated with pigmentation by increasing tyrosinase activity [39-44]. In our results, morin expression levels increased between 0 and $15 \mathrm{~min}$ in phosphorylated ERK and decreased after $15 \mathrm{~min}$. These results indicate that the melanin synthesis effects of morin resulted from inhibition of ERK-dependent degradation of MITF. Phosphorylated p38 showed increased expression levels between 0 and $30 \mathrm{~min}$. These results indicate that $\mathrm{p} 38$ also contributes to the melanin synthesis effect of morin. Therefore, we next confirmed the mechanism by treatment with PD98059 (ERK inhibitor), SP600125 (JNK inhibitor), and SB203580 (p38 inhibitor). As a result, ERK and p38 inhibitors inhibited morin-induced melanin synthesis. However, the JNK inhibitor did not affect melanin synthesis. It is thought that the contributions of JNK signaling is relatively weaker than ERK and p38 in the MAPK pathway.

Taken together, our results suggest that morin enhances melanin production by upregulating MITF through the activation of ERK and p38 signaling pathways in B16F10 mouse melanoma cells (Figure 7). Several treatment methods and therapeutics, such as skin graft, lasers, vitamin D analogs, and steroids, have been used to treat vitiligo, but these methods have not been widely used because they cause long-term side effects [45,46]. From this point of view, morin is considered to be a good candidate for the treatment of vitiligo if further studies, such as efficacy and safety evaluation on humans, are successfully carried out. 


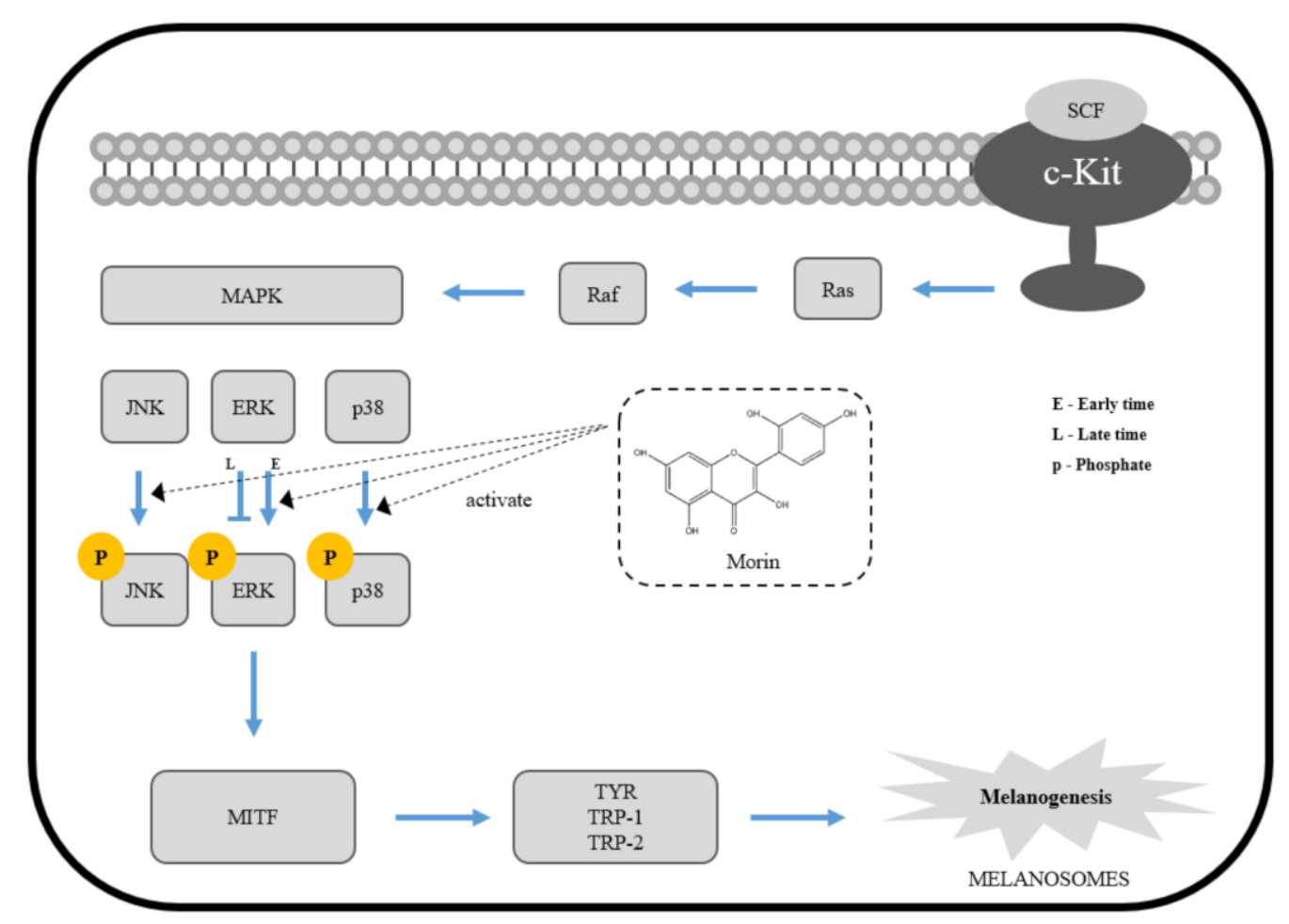

Figure 7. The mechanism of morin-induced melanogenesis in B16F10 mouse melanoma cells.

\section{Materials and Methods}

\subsection{Materials}

Morin was purchased from Sigma-Aldrich (St. Louis, MO, USA). Antibodies against MITF (\#12590), p-ERK (\#9101), ERK (\#9102), p-JNK (\#4668), p-p38 (\#4511), and PD98059 were purchased from Cell Signaling Technology (Beverly, MA, USA). GAPDH was purchased from Enogene (Nanjing, China). TRP-1 (sc-166857), JNK (sc-571), and p38 (H-147) were purchased from Santa Cruz Biotechnology (Santa Cruz, CA, USA). TRP-2 (ab221144) was purchased from Abcam (Cambridge, MA, USA). DMEM, fetal bovine serum (FBS), penicillin/streptomycin, and trypsin-ethylenediaminetetraacetic acid were purchased from Gibco (Grand Island, NY, USA). Dimethyl sulfoxide (DMSO), $\alpha-\mathrm{MSH}, \mathrm{NaOH}, 3-$ (4,5-dimethylthiazol-2-yl)-2,5-diphenyltetrazolium bromide (MTT), and 3,4-dihydroxy-Lphenlyanine (L-DOPA) were obtained from Sigma-Aldrich (St. Louis, MO, USA). SP600125 and SB203580 were purchased from Cayman Chemical (Ann Arbor, MI, USA). Pro-Prep lysis buffer was purchased from iNTRON Biotechnology (Seoul, Korea).

\subsection{Cell Culture and Treatment}

B16F10 melanoma cells (CRL-6475) were obtained from ATCC (American Type Culture Collection, Manassas, VA). B16F10 cells were cultured in Dulbecco's modified Eagle's medium (DMEM), supplemente with 10\% fetal bovine serum (FBS) and 1\% penicillinstreptomycin $(\mathrm{P} / \mathrm{S})$. The cells were incubated in a humidified atmosphere of $5 \% \mathrm{CO}_{2}$ at $37^{\circ} \mathrm{C}$.

\subsection{Measurement of Cell Viability}

Cell viability was examined by the MTT assay. Briefly, B16F10 mouse melanoma cells were incubated for $24 \mathrm{~h}$ in the culture medium. The cells were seeded at a density of $2 \times 10^{4}$ cells/well in 96 -well plates and incubated with various concentrations of morin $(5-100 \mu \mathrm{M})$ for $48 \mathrm{~h}$. After incubation, the cells were treated with MTT (dissolved in DMEM to $5 \mathrm{mg} / \mathrm{mL}$ ) for $3 \mathrm{~h}$. Following removal of the medium, $200 \mu \mathrm{L}$ of DMSO was added to 
each well, and plates were gently shaken for $15 \mathrm{~min}$. Absorbance was measured at $570 \mathrm{~nm}$ using a UV/Vis microplate reader (Thermo Fisher Scientific, Multiskan Sky, Seoul, Korea).

\subsection{Measurement of Melanin Content}

Melanin content was measured and analyzed using a previously described method with slight modifications [47]. Briefly, B16F10 mouse melanoma cells were incubated for $24 \mathrm{~h}$ in the culture medium. The medium was replaced with fresh medium containing morin at $25-100 \mu \mathrm{M}$, and $\alpha$-MSH $(100 \mathrm{nM})$ was used as a positive control and incubated for $72 \mathrm{~h}$ more. Cell pellets were dissolved in $1 \mathrm{~N}$ of $\mathrm{NaOH}$ in $10 \% \mathrm{DMSO}$ at $80{ }^{\circ} \mathrm{C}$ for $1 \mathrm{~h}$. Absorbance was measured at $475 \mathrm{~nm}$ using a UV/Vis microplate reader (Thermo Fisher Scientific, Multiskan Sky, Seoul, Korea).

\subsection{Measurement of Mushroom Tyrosinase Activity}

The effect of morin on mushroom tyrosinase activity was measured in a cell-free system [48]. As a substrate for tyrosinase activity, L-DOPA at a concentration of $10 \mathrm{mM}$ was dissolved in sodium phosphate buffer $(67 \mathrm{mM}, \mathrm{pH}=6.8)$. After $10 \mathrm{~min}$, the absorbance was measured at $475 \mathrm{~nm}$ using a UV/Vis microplate reader (Thermo Fisher Scientific, Multiskan Sky, Seoul, Korea).

\subsection{Measurement of Intracellular Tyrosinase Assay}

Intracellular tyrosinase activity was estimated by measuring the rate of L-DOPA oxidation as previously described, with certain modifications [49]. B16F10 melanoma cells were treated as described previously above. To measure cellular tyrosinase activity, cells were washed with cold PBS and lysed with RIPA buffer. The cell lysates were clarified by centrifugation at $32,127 \times g$ for $5 \mathrm{~min}$. The lysates $(30 \mu \mathrm{g})$ were dissolved in $0.1 \mathrm{M}$ of sodium phosphate buffer $(\mathrm{pH}=6.8)$ and treated with L-dopa $(1 \mathrm{mg} / \mathrm{mL})$ in a 96 -well plate at $37^{\circ} \mathrm{C}$ for $1 \mathrm{~h}$. Absorbance was measured at $475 \mathrm{~nm}$ using a UV/Vis microplate reader (Thermo Fisher Scientific, Multiskan Sky, Seoul, Korea).

\subsection{Western Blotting}

B16F10 cells were seeded at a density of $3 \times 10^{5}$ cells/well in a $60 \mathrm{~mm}$ dish and incubated with various concentrations of morin and $\alpha-\mathrm{MSH}$. Cells were washed with cold PBS and lysed in buffer for $20 \mathrm{~min}$ on ice. Cell lysates were centrifuged at 32,127 $\times \mathrm{g}$ for $5 \mathrm{~min}$ at $4^{\circ} \mathrm{C}$. Lysed supernatant protein was measured by the Bradford assay. The protein $(10 \mu \mathrm{g})$ was separated with $10 \%$ sodium dodecyl sulfate polyacrylamide gel electrophoresis (SDS-PAGE) and transferred to the polyvinylidene difluoride (PVDF) membrane. The PVDF membrane was incubated for $1 \mathrm{~h}$ in blocking buffer (5\% skim milk and $0.1 \%$ Tween 20 in TBS). The membrane was incubated with the primary antibody for $24 \mathrm{~h}$ at $4{ }^{\circ} \mathrm{C}$. GAPDH was used as an internal control. After washing four times with TBS containing $0.1 \%$ Tween 20 , the membrane was incubated with horseradish peroxidase-conjugated anti-mouse and anti-rabbit secondary antibodies for $1 \mathrm{~h}$ at room temperature. Protein band detection on the PVDF membrane was performed using Western Bright ${ }^{\mathrm{TM}}$ ECL reagent and a C300 chemiluminescence imager.

\subsection{Statistical Analysis}

The values for the independent experiments were expressed as mean \pm standard deviation (mean $\pm \mathrm{SD}$ ), and statistical significance was determined using Student's $t$-test and ANOVA. All statistical analyses were compared using the SPSS statistical software $22.0 ;^{*} p<0.05,{ }^{* *} p<0.01,{ }^{* *} p<0.001$ values were considered significant differences.

\section{Conclusions}

In this study, we demonstrated that morin induced melanin synthesis and tyrosinase activity by accelerating ERK and p38 signaling pathways in B16F10 mouse melanoma cells. 
Taken together, these results suggest that morin may be a potential therapeutic supplement for the improvement of disorders such as hypopigmentation.

Author Contributions: Conceptualization, S.S., J.K., and K.P.; Methodology, S.S. and J.K.; Formal analysis, J.K.; Investigation, S.S., J.K., M.K., and N.S.; Project administration, K.P.; Supervision, K.P.; Writing, original draft preparation, S.S. and J.K.; Writing, review and editing, K.P. All authors have read and agreed to the published version of the manuscript.

Funding: This research was funded by the Basic Science Research Program through the National Research Foundation of Korea (NRF) and funded by the Ministry of Education (grant number 2018R1D1A1B07050948).

Institutional Review Board Statement: Not applicable.

Conflicts of Interest: The authors declare no conflict of interest.

Sample Availability: Samples of the compounds are not available from the authors.

\section{References}

1. Chakraborty, D.P.; Roy, S.; Chakraborty, A.K. Vitiligo, psoralen, and melanogenesis. Pigment Cell Res. 1996, 9, 107-116. [CrossRef]

2. Mohamed, A.; Hassan, R. Concise review of recent studies in vitiligo. Qatar Med. J. 2013, 2, 10.

3. Rebat, M.H.; Johnathan, L.C. Vitiligo update. Semin. Cutan. Med. Surg. 2009, 28, 86-92.

4. Namazi, M.R. Neurogenic dysregulation, oxidative stress, autoimmunity, and melanocytorrhagy in vitiligo: Can they be interconnected? Pigment Cell Res. 2007, 20, 360-363. [CrossRef] [PubMed]

5. Niu, C.; Aisa, H.A. Upregulation of Melanogenesis and Tyrosinase Activity: Potential Agents for Vitiligo. Molecules 2017, $22,1303$. [CrossRef] [PubMed]

6. Kumari, S.; Thng, S.; Verma, N.; Gautam, H. Melanogenesis Inhibitors. Acta Derm. Venereol. 2018, 98, 924-931. [CrossRef]

7. Chang, T.S. Natural melanogenesis inhibitors acting through the down-regulation of tyrosinase activity. Materials 2012, 5, 1661-1685. [CrossRef]

8. Chen, W.S.; Tseng, T.S.; Hsiao, N.W.; Lin, Y.L.; Wen, Z.H.; Tsai, C.C.; Lee, Y.C.; Lin, H.H.; Tsai, K.C. Discovery of highly potent tyrosinase inhibitor, T1, with significant anti-melanogenesis ability by zebrafish in vivo assay and computational molecular modeling. Sci. Rep. 2015, 5, 7995. [CrossRef]

9. Korner, A.; Pawelek, J. Mammalian tyrosinase catalyzes three reactions in the biosynthesis of melanin. Science 1982, 217, 1163-1165. [CrossRef]

10. Lee, S.Y.; Baek, N.H.; Nam, T.G. Natural, semisynthetic and synthetic tyrosinase inhibitors. J. Enzym. Inhib. Med. Chem. 2016, 31, 1-13. [CrossRef]

11. Kobayashi, T.; Urabe, K.; Winder, A.; Jimenez-Cervantes, C.; Imokawa, G.; Brewington, T.; Solano, F.; Garcia-Borron, J.C.; Hearing, V.J. Tyrosinase related protein 1 (TRP1) functions as a DHICA oxidase in melanin biosynthesis. EMBO J. 1994, 13, 5818-5825. [CrossRef] [PubMed]

12. Hellier, F.F. Melanogenesis. BMJ 1968, 3, 421. [CrossRef]

13. D'Mello, S.A.; Finlay, G.J; Baguley, B.C.; Askarian-Amiri, M.E. Signaling pathways in melanogenesis. Int. J. Mol. Sci. 2016, 17, 1144. [CrossRef]

14. Feng, Z.C.; Riopel, M.; Popell, A.; Wang, R. A survival Kit for pancreatic beta cells: Stem cell factor and c-Kit receptor tyrosine kinase. Diabetologia 2015, 58, 654-665. [CrossRef] [PubMed]

15. Li, P.H.; Liu, L.H.; Chang, C.C.; Gao, R.; Leung, C.H.; Ma, D.L.; David Wang, H.M. Silencing Stem Cell Factor Gene in Fibroblasts to Regulate Paracrine Factor Productions and Enhance c-Kit Expression in Melanocytes on Melanogenesis. Int. J. Mol. Sci. 2018, 19, 1475. [CrossRef]

16. Wijeratne, S.S.; Abou-Zaid, M.M.; Shahidi, F. Antioxidant Polyphenols in Almond and Its Coproducts. J. Agric. Food Chem. 2006, 54, 312-318. [CrossRef]

17. Romero, I.; Paez, A.; Ferruelo, A.; Lujan, M.; Berenguer, A. Polyphenols in red wine inhibit the proliferation and induce apoptosis of LNCaP cells. BJU Int. 2002, 89, 950-954. [CrossRef]

18. Hu, J.; Guo, X.; Yang, L. Morin inhibits proliferation and self-renewal of CD133+ melanoma cells by upregulating miR-216a. J. Pharmacol. Sci. 2018, 136, 114-120. [CrossRef]

19. Prahalathan, P.; Kumar, S.; Raja, B. Morin attenuates blood pressure and oxidative stress in deoxycorticosterone acetate-salt hypertensive rats: A biochemical and histopathological evaluation. Metabolism 2012, 61, 1087-1099. [CrossRef]

20. Hanasaki, Y.; Ogawa, S.; Fukui, S. The correlation between active oxygens scavenging and antioxidative effects of flavonoids. Free Radic. Biol. Med. 1994, 16, 845-850. [CrossRef]

21. Fang, S.H.; Hou, Y.C.; Chang, W.C.; Hsiu, S.L.; Chao, P.D.; Chiang, B.L. Morin sulfates/glucuronides exert anti-inflammatory activity on activated macrophages and decreased the incidence of septic shock. Life Sci. 2003, 74, 743-756. [CrossRef]

22. Yac, C.; Jin, C.L.; Oh, I.G.; Park, C.H.; Chung, J.H. Melia azedarach extract stimulates melanogenesis through increase of tyrosinase-related protein 1 expression in B16F10 mouse melanoma cells. Int. J. Mol. Med. 2015, 35, 1761-1766. 
23. Niu, C.; Yin, L.; Aisa, H.A. Novel Furocoumarin Derivatives Stimulate Melanogenesis in B16 Melanoma Cells by Up-Regulation of MITF and TYR Family via Akt/GSK3 $\beta$ / $\beta$-Catenin Signaling Pathways. Int. J. Mol. Sci. 2018, 19, 746. [CrossRef] [PubMed]

24. Hwang, Y.S.; Oh, S.; Park, S.H.; Lee, J.; Kwon, K.; Park, S.J.; Kim, J.; Yu, E.; Cho, J.Y.; Lee, J. Melanogenic Effects of Maclurin Are Mediated through the Activation of cAMP/PKA/CREB and p38 MAPK/CREB Signaling Pathways. Oxid. Med. Cell. Longev. 2019, 2019, 9827519.

25. Wang, J.Y.; Chen, H.; Wang, Y.Y.; Wang, X.Q.; Chen, H.Y.; Jhang, M.; Tang, Y.; Zhang, B. Network pharmacological mechani of Vernonia anthelmintica (L.) in the treatment of vitiligo: Isorhamnetin induction of melanogenesis via up-regulation of melaninbiosynthetic genes. BMC Syst. Biol. 2017, 11, 103. [CrossRef] [PubMed]

26. Aggarwal, B.B.; Shishodia, S. Molecular targets of dietary agents for prevention and therapy of cancer. Biochem. Pharmacol. 2006, 71,1397-1421. [CrossRef]

27. Kim, J.W.; Lee, J.H.; Hwang, B.Y.; Mun, S.H.; Ko, N.Y.; Kim, D.K.; Kim, B.; Kim, H.S.; Kim, Y.M.; Choi, W.S. Morin inhibits Fyn kinase in mast cells and IgE-mediated type I hypersensitivity response in vivo. Biochem. Pharmacol. 2009, 77, 1506-1512. [CrossRef]

28. Wang, J.; Guo, C.; Wei, Z.; He, X.; Kou, J.; Zhou, E.; Yang, Z.; Fu, Y. Morin suppresses inflammatory cytokine expression by downregulation of nuclear factor- $\mathrm{kB}$ and mitogen-activated protein kinase (MAPK) signaling pathways in lipopolysaccharidestimulated primary bovine mammary epithelial cells. J. Dairy Sci. 2016, 99, 3016-3022. [CrossRef]

29. Mamat, N.; Lu, X.Y.; Kabas, M.; Aisa, H.A. Potential anti-vitiligo properties of cynarine extracted from Vernonia anthelmintica (L.) Willd. Int. J. Mol. Med. 2018, 42, 2665-2675. [CrossRef]

30. Jang, J.Y.; Kim, H.N.; Kim, Y.R.; Choi, Y.H.; Kim, B.W.; Shin, H.K.; Choi, B.T. Aqueous fraction from Cuscuta japonica seed suppresses melanin synthesis through inhibition of the p38 mitogen-activated protein kinase signaling pathway in B16F10 cells. J. Ethnopharmacol. 2012, 141, 338-344. [CrossRef]

31. Jang, J.Y.; Kim, H.N.; Kim, Y.R.; Choi, W.Y.; Choi, Y.H.; Shin, H.K.; Choi, B.T. Partially purified components of Nardostachys chinensis suppress melanin synthesis through ERK and Akt signaling pathway with cAMP down-regulation in B16F10 cells. J. Ethnopharmacol. 2011, 137, 1207-1214. [CrossRef] [PubMed]

32. Hemesath, T.J.; Price, E.R.; Takemoto, C.; Badalian, T.; Fisher, D.E. MAP kinase links the transcription factor Microphthalmia to c-Kit signalling in melanocytes. Nature 1998, 391, 298-301. [CrossRef]

33. Tsang, T.F.; Chan, B.; Tai, W.C.; Huang, G.; Wang, J.; Li, X.; Jiang, Z.H.; Hsiao, W.L.W. Gynostemma pentaphyllum saponins induce melanogenesis and activate cAMP/PKA and Wnt/ $\beta$-catenin signaling pathways. Phytomedicine 2019, 60, 153008. [CrossRef]

34. Zhou, J.; Ren, T.; Li, Y.; Cheng, A.; Xie, W.; Xu, L.; Peng, L.; Lin, J.; Lian, L.; Diao, Y.; et al. Oleoylethanolamide inhibits $\alpha$-melanocyte stimulating hormone-stimulated melanogenesis via ERK, Akt and CREB signaling pathways in B16 melanoma cells. Oncotarget 2017, 8, 56868-56879. [CrossRef] [PubMed]

35. Drira, R.; Sakamoto, K. Sakuranetin Induces Melanogenesis in B16BL6 Melanoma Cells through Inhibition of ERK and PI3K/AKT Signaling Pathways. Phytother. Res. 2016, 30, 997-1002. [CrossRef] [PubMed]

36. Uto, T.; Ohta, T.; Yamashita, A.; Fujii, S.; Shoyama, Y. Liquiritin and Liquiritigenin Induce Melanogenesis via Enhancement of p38 and PKA Signaling Pathways. Medicines 2019, 6, 68. [CrossRef] [PubMed]

37. Drira, R.; Sakamoto, K. Isosakuranetin, a 4'-O-methylated flavonoid, stimulates melanogenesis in B16BL6 murine melanoma cells. Life Sci. 2015, 143, 43-49. [CrossRef] [PubMed]

38. Jung, E.; Kim, J.H.; Kim, M.O.; Jang, S.; Kang, M.; Oh, S.W.; Nho, Y.H.; Kang, S.H.; Kim, M.H.; Park, S.H.; et al. Afzelin positively regulates melanogenesis through the p38 MAPK pathway. Chem. Biol. Interact. 2016, 254, 167-172. [CrossRef]

39. Zhao, L.M.; Sun, G.G.; Han, L.N.; Liu, L.H.; Ren, F.Z.; Li, L.; Ma, M.; Shan, B.E. P-Hydroxycinnamaldehyde Induces B16-F1 Melanoma Cell Differentiation via the RhoA-MAPK Signaling Pathway. Cell. Physiol. Biochem. 2016, 38, 2247-2260. [CrossRef]

40. Selimovic, D.; Hassan, M.; Haikel, Y.; Hengge, U.R. Taxol-induced mitochondrial stress in melanoma cells is mediated by activation of c-Jun N-terminal kinase (JNK) and p38 pathways via uncoupling protein 2. Cell. Signal. 2008, 20, 311-322. [CrossRef]

41. Chang, S.P.; Huang, H.M.; Shen, S.C.; Lee, W.R.; Chen, Y.C. Nilotinib induction of melanogenesis via reactive oxygen speciesdependent JNK activation in B16F0 mouse melanoma cells. Exp. Dermatol. 2018, 27, 1388-1394. [CrossRef]

42. Jiang, Z.; Xu, J.; Long, M.; Tu, Z.; Yang, G.; He, G. 2,3,5,4'-tetrahydroxystilbene-2-O- $\beta$-d-glucoside (THSG) induces melanogenesis in B16 cells by MAP kinase activation and tyrosinase upregulation. Life Sci. 2009, 85, 345-350. [CrossRef] [PubMed]

43. Zhou, J.; Shang, J.; Ping, F.; Zhao, G. Alcohol extract from Vernonia anthelmintica (L.) willd seed enhances melanin synthesis through activation of the p38 MAPK signaling pathway in B16F10 cells and primary melanocytes. J. Ethnopharmacol. 2012, 143, 639-647. [CrossRef]

44. Ahn, J.H.; Jin, S.H.; Kang, H.Y. LPS induces melanogenesis through p38 MAPK activation in human melanocytes. Arch. Dermatol. Res. 2008, 300, 325-329. [CrossRef] [PubMed]

45. Li, K.; Shi, Q.; Yang, L.; Li, X.; Liu, L.; Wang, L.; Li, Q.; Wang, G.; Li, C.Y.; Gao, T.W. The association of vitamin D receptor gene polymorphisms and serum 25-hydroxyvitamin D levels with generalized vitiligo. Br. J. Dermatol. 2012, 167, 815-821. [CrossRef]

46. Picardo, M.; Dell'Anna, M.L.; Ezzedine, K.; Hamzavi, I.; Harris, J.E.; Parsad, D.; Taieb, A. Vitiligo. Nat. Rev. Cisease Primers 2015, 1, 15011. [CrossRef] [PubMed]

47. Alam, M.B.; Ahmed, A.; Motin, M.A.; Kim, S.; Lee, S.H. Attenuation of melanogenesis by Nymphaea nouchali (Burm. f) flower extract through the regulation of cAMP/CREB/MAPKs/MITF and proteasomal degradation of tyrosinase. Sci. Rep. 2018, 8, 13928. [CrossRef] [PubMed] 
48. Shi, Y.; Chen, Q.X.; Wang, Q.; Song, K.K.; Qiu, L. Inhibitory effects of cinnamic acid and its derivatives on the diphenolase activity of mushroom (Agaricus bisporus) tyrosinase. Food Chem. 2005, 92, 707-712. [CrossRef]

49. Hwang, Y.S.; Kim, Y.J.; Kim, M.O.; Kang, M.G.; Oh, S.W.; Nho, Y.H.; Park, S.H.; Lee, J.S. Cannabidiol upregulates melanogenesis through CB1 dependent pathway by activating p38 MAPK and p42/44 MAPK. Chem. Biol. Interact. 2017, 273, 107-114. [CrossRef] [PubMed] 